\title{
Do human B-lymphocytes avoid aging until 60 years?
}

\author{
Andrea Knight ${ }^{1,2, *}$, Pavel Nemec ${ }^{1}$, Sona Bretzova ${ }^{1,5}$, Lucie Valkova ${ }^{1,5}$, Marketa \\ Kolmanova ${ }^{1,5}$, Renata Vytopilova ${ }^{1,5}$, Marek Havelka ${ }^{1,5}$, Pavla Vsianska ${ }^{3}$, Lucie \\ Rihova ${ }^{3}$, Marta Krejci ${ }^{4}$ and Martin Piskacek ${ }^{1,5, *}$ \\ ${ }^{1}$ Department of Pathological Physiology, Faculty of Medicine, Masaryk University Brno, Brno, Czech Republic \\ ${ }^{2}$ Gamma-Delta T Cell Laboratory, University Hospital Brno, Brno, Czech Republic \\ ${ }^{3}$ Department of Clinical Haematology, University Hospital Brno, Brno, Czech Republic \\ ${ }^{4}$ Department of Internal Medicine, Haematology and Oncology, University Hospital Brno, Brno, Czech Republic \\ ${ }^{5}$ Laboratory of Cancer Biology and Genetics, University Hospital Brno, Brno, Czech Republic \\ * These authors have contributed equally to the study and should be considered as joint senior authors
}

Correspondence to: Martin Piskacek, email: Piskacek@med.muni.cz

Keywords: aging, B cell, naive B cells, IL7R, GEP, Gerotarget

Received: March 25, $2016 \quad$ Accepted: June 03, 2016

Published: June 17, 2016

\section{ABSTRACT}

Broad changes in human innate and adaptive immunity are associated with advanced age. The age-related alteration of gene expression was reported for both $T$ and $B$ lymphocytes. We analysed the genome-wide expression profiles $(n=20)$ of naive and whole $B$ cell populations from young and early aged healthy donors under 60 years. We revealed large homogeneity of all analysed genome-wide expression profiles but did not identified any significant gene deregulation between young (3045 years) and early aged healthy donors (50-60 years). We argue that $B$ cells avoid the aging program on molecular level until 60 years of age. Our results demonstrate the potential of hematopoietic stem cells to generate uncompromised lymphocytes in early elderly. These are very encouraging findings for the general health and the immunity maintenance would not need any intervention to naive B cells. Rather, a suitable immune stimulation in healthy body environment warrants further research into aging of older elderly.

\section{INTRODUCTION}

The immunosenescence is a natural and inevitable process characterized by a declined immunity. Lymphocytes play a central role in the establishment and maintenance of protective immunity. The lymphoid progenitor counts decline with the advancing age and their repertoire is less diverse in elderly [1-4]. The aging of B cells on molecular level and increased vulnerability to ageassociated malignancies was reported for the advanced elderly [5-11]. Similarly, the B cell aging was observed in mouse model, where it was linked with Interleukin 7 pathway [12-16].

The prevalence of $\mathrm{B}$ cell malignancies, such as Chronic Lymphocytic Leukaemia (CLL), Multiple Myeloma (MM) and Diffuse Large B Cell Lymphoma (DLBCL), rapidly increases with advancing age.
According to SEER Cancer Statistics, only about 4\% of newly diagnosed patients are diagnosed with these malignancies under the age of 44 years (http://seer.cancer. gov/statfacts $/ \mathrm{html} / \mathrm{mulmy} . \mathrm{html}$ ). The increasing incidence of $12 \%$ was reported for the next decade (between 45 and 54 years) and remains constant in a range of $21 \%$ to $27 \%$ in newly diagnosed patients per decade between $55-85$ years of age. The sigmoid course of this incidence has prompted our interest to investigate B cells in the context of aging below the 60 years.

In this study we determined the genome-wide gene deregulation in B cells in early elderly to address the programmed gene deregulation linked with decline of immunity and precondition for aged associated B cell malignancies. 


\section{RESULTS}

\section{Aging in naive B cells (GEP, $n=12)$}

We have collected peripheral blood samples of young (30-45 years) and old (55-60 years) healthy donors. Naive B cells defined as $\mathrm{CD} 19^{+} \mathrm{CD} 27^{-}$were isolated by MACS sorting. The age, gender and purity of each cell sample are shown (Table 1).

The age-specific genome-wide analyses $(n=12)$ have been determined in three independent sets named GEP-N1, GEP-N2 and GEP-N3, each consisting of four samples (Figure 1). The data for age-specific gene deregulation were collected with the threshold of $10 \%$ fold change between young and old donors. From a total of 22,660 annotated genes, we detected 351 deregulated genes for GEP-N1 set, 56 genes for GEP-N2, and 21 genes for GEP-N3. All non-coding RNA, pseudogenes and olfactory receptors were excluded from our analyses.

The samples in GEP-N1 set had the lowest purity $(88 \%)$ and therefore were positive also for genes that are expressed in other cell populations including monocytes, T or NK cells. According to the BioGPS database (http:// biogps.org/\#goto = genereport\&id = 22914), genes such as KLRK1 and Annexin A1 are expressed about 160 fold more in CD8 (T cells) and CD33 (myeloid cells) than in $\mathrm{B}$ cells. The genes of lineage-specific contamination in our samples were not detected in sets with higher purity (GEP-N2 set with 96\% purity and GEP-N3 set with 99\% purity). The summary result of genome-wide profiles in the GEP-N1, GEP-N2 and GEP-N3 sets involving naive B cell did not revealed any shared gene (Figure 1).

\section{Gender specific gene in naive B cells (GEP, $n=3$ female +5 male)}

Next, we aimed to detect gender specific genes in naïve B cells to justify credibility of our samples. The DDX3Y, EIF1AY, KDM5D and RPS4Y1 were reported as gender specific genes in B lymphocytes [17] [18]. We analysed the expression of gender specific genes in male $(n=5)$ versus female $(n=3)$ in sets GEP-N2 and GEP-N3 (Figure 2). Of note, GEP-N1 set consisted only of male samples and therefore has not been used here.

We identified several genes including DDX3Y, EIF1AY, KDM5D, RPS4Y1, PRKY, TTY10, TXLNG2P, USP9Y, UTY, and ZFY that are expressed from narrow chromosomal bands Yq11.2 and Yq11.221-223 located on chromosome Y, two genes DNAJC24, RGS18 as lineagespecific contamination according to the expression data in BioGPS database and gene EYS located on chromosome 6 as a representing noise in our experiment.
Table 1: Healthy donors' information and cell sample purity after MACS cell sorting.

\begin{tabular}{|l|l|l|l|l|}
\hline GEP-N1 & Donor & Age & Gender & purity \% \\
\hline & $4461-1973$ & 41 & male & 98,5 \\
\hline & $4945-1976$ & 38 & male & 93,0 \\
\hline & $4453-1958$ & 56 & male & 89,8 \\
\hline & $4948-1956$ & 58 & male & 87,7 \\
\hline & & & & \\
\hline GEP-N2 & Donor & Age & Gender & purity \% \\
\hline & $8947-1980$ & 34 & male & 99,7 \\
\hline & $9021-1973$ & 41 & female & 96,5 \\
\hline & $8960-1957$ & 57 & male & 99,5 \\
\hline & $9025-1954$ & 60 & female & 99,0 \\
\hline & & & & \\
\hline GEP-N3 & Donor & Age & Gender & purity \% \\
\hline & $3556-1984$ & 31 & male & 99,1 \\
\hline & $3885-1985$ & 30 & male & 99,4 \\
\hline & $3521-1957$ & 58 & male & 99,5 \\
\hline & $4402-1957$ & 58 & female & 99,2 \\
\hline & & & & \\
\hline GEP-B1 & Donor & Age & Gender & purity \% \\
\hline & $8947-1980$ & 34 & male & 92,0 \\
\hline & $9021-1973$ & 41 & female & 96,4 \\
\hline & $8960-1957$ & 57 & male & 95,8 \\
\hline & $9025-1954$ & 60 & female & 95,0 \\
\hline & & & & \\
\hline GEP-B2 & Donor & Age & Gender & purity \% \\
\hline & $3556-1984$ & 31 & male & 99,1 \\
\hline & $3885-1985$ & 30 & male & 99,0 \\
\hline & $3521-1957$ & 58 & male & 99,6 \\
\hline & $4402-1957$ & 58 & female & 99,5 \\
\hline & & & & \\
\hline & & & \\
\hline & &
\end{tabular}

\section{Male specific aging in naive B cells $(\mathrm{GEP}, \boldsymbol{n}=9)$}

Hypothetically, aging could differ in males and females. Therefore we excluded all females from sets GEP-N1, GEP-N2 and GEP-N3.

In the gender specific experimental set, male samples $(n=9)$ were included and $15 \%$ fold change threshold was applied. The resulting six deregulated genes were recognized as lineage-specific contamination or as an experimental noise. The CD36, CLC, F13A1, KLRC4-K1, PLXDC2 genes are largely expressed in diverse subpopulations of leukocytes including CD3 (T cells), CD14 (monocytes), CD33 (myeloid cells), CD56 (NK cells) positive cells, eosinophils and basophils, but hardly in B cells (BioGPS). The single gene not linked with lineage-specific contamination was C12orf39 gene coding for neuropeptide Spexin. We evaluated this paracrine hormone as a false positive resulting from noise in our experiments (see bellow for further supporting exclusion evidence in results for B cell population). The analyses of the gender restricted genome-wide profiles 


\section{GEP-N1}

Naive B cell $(n=4)$

Threshold 10\%

Deregulation in $\mathbf{3 5 1}$ genes from 22660

Population purity $>\mathbf{8 8} \%$

Lineage contamination: $\mathbf{2 1 9}$ genes

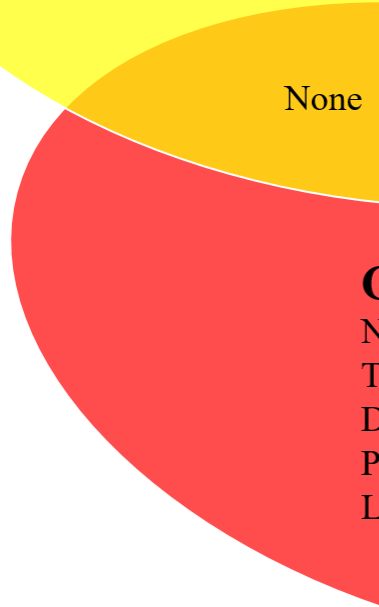

\section{GEP-N2}

Naive B cell $(\mathrm{n}=4)$

Threshold 10\%

Deregulation in $\mathbf{5 6}$ genes from 22660

Population purity $>96 \%$

Lineage contamination: 1

\section{GEP-N3}

$\begin{array}{lll}\uparrow & \text { ANXA1 } & \uparrow \\ \uparrow & \text { KLRC4-K1 } & \downarrow \\ \uparrow & \text { OR5M3 } & \uparrow \\ \uparrow & \text { ND6 } & \uparrow\end{array}$

Naive B cell $(\mathrm{n}=4)$

Threshold 10\%

Deregulation in 21 genes from 22660

Population purity $>\mathbf{9 9} \%$

Lineage contamination: 3 genes

Figure 1: Aging in naive cells (genome-wide profiles, $\boldsymbol{n}=\mathbf{1 2}$ ). Venn diagram of results from whole-genome experimental sets GEP-N1, GEP-N2 and GEP-N3 for age-specific genes in naive B cells. The three independent experiments have been conducted, each comprised of four samples have been analysed. Arrows indicate expression upregulation and downregulation with age.

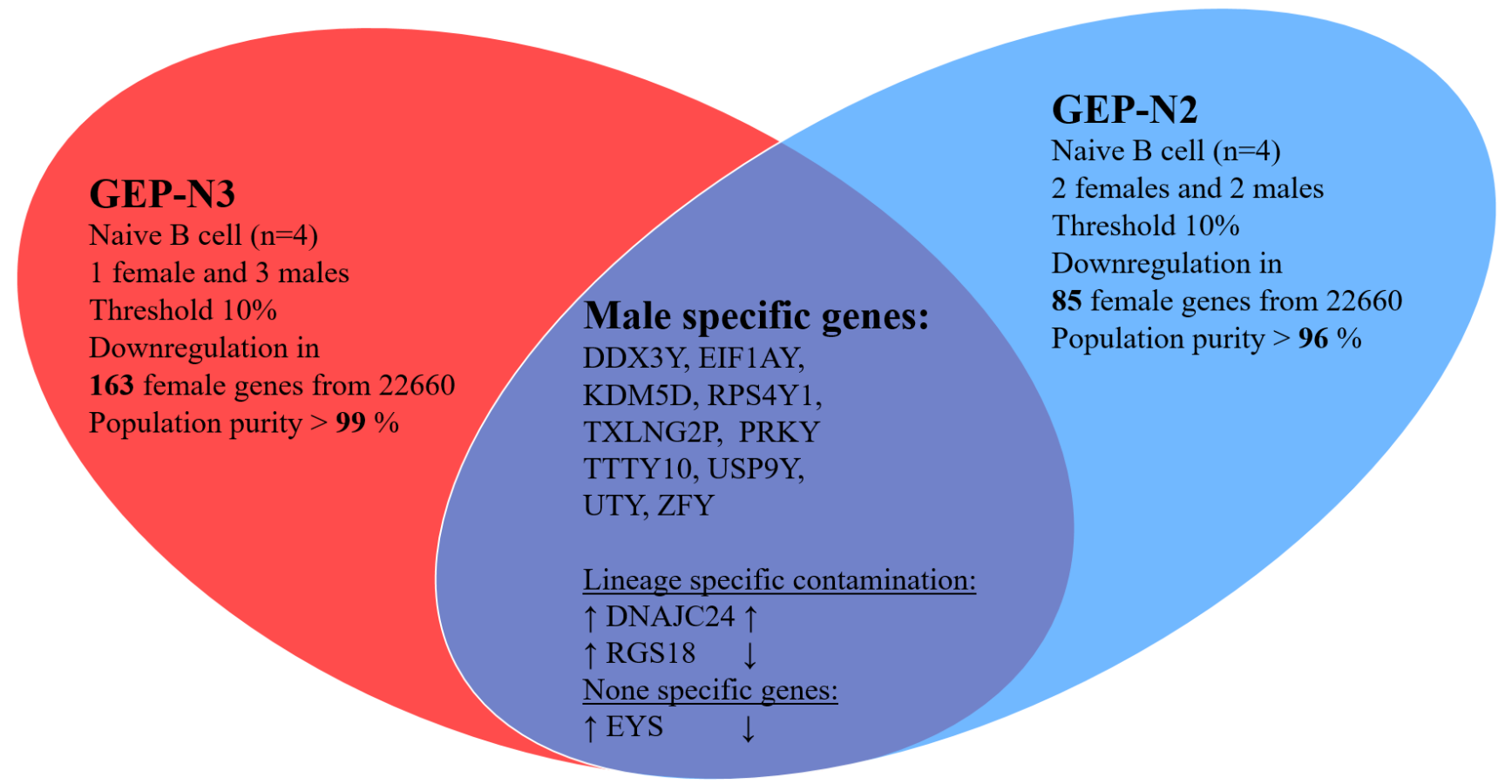

Figure 2: Gender specific gene in naive cells (genome-wide profiles, $\boldsymbol{n}=\mathbf{8}$ ). Venn diagram of results from whole-genome experimental sets GEP-N2 and GEP-N3 for gender specific genes in naive B cells. In two independent sets, three females and five male samples were investigated. Arrows indicate expression upregulation and downregulation in male. 
in the GEP-N1, GEP-N2 and GEP-N3 sets but did not revealed any shared age-specific gene (Figure 3 ).

\section{Aging in B cell population (GEP, $n=8)$}

We analysed gene deregulation of whole B cell population $(n=8)$ in two independent experimental sets, GEP-B1 and GEP-B2, each consisting of four samples. The analyses of the genome-wide analyses in the GEP-B1 and GEP-B2 sets did not revealed any shared age-specific gene (Figure 4).

\section{Interleukin 7 receptor signalling in elderly (GEP, $n=20$; western blotting, $n=8$ )}

It has been know that the Interleukin 7 (IL7) signalling declines in elderly as reported in old mice [12, 13]. The IL7 signalling associates with human natural ageing and longevity [8].

From the animal model, the IL7 responsiveness is linked with the decline of B cell progenitors. Interestingly, gender specific regulation of the IL7 receptor (IL7R) was reported in human B lymphocytes [17]. However, we did not observe any changes in expression of neither targets of
IL7R pathway nor IL7R (GEP-N1, N2, N3, B2 and B3). Consistently, we did not observe any IL7R expression changes on protein level (Figure 5).

\section{DISCUSSION}

In this study, we examined age-specific gene deregulated in naive and whole $B$ cell populations in two cohorts of young and early aged healthy donors. We did not identify a single gene to be age-specifically deregulated in our groups of young (30-45 years) and early aged (55-60 years) healthy donors. We observed largely homogenous and overall consistent genome-wide expression in all 20 samples examined. These results strongly indicate that $\mathrm{B}$ cells avoid aging program until 60 years of age.

We have excluded non-coding RNAs, olfactory receptors and pseudogenes, although these genes maybe involve in aging process too. The regulatory miRNAs were reported to be age-specifically deregulated in donors exceeding 60 years $[5,19,20]$. In this respect, we conclude from our results, that they did not significantly alter genome-wide expression of annotated protein-coding genes monitored in our analyses (GEP-N1, N2, N3, B2 and B3).

\section{GEP-N1}

Naive B cell $(\mathrm{n}=4$, male)

Threshold 15\%

Deregulation in $\mathbf{1 8 9}$ genes from 22660

Population purity $>\mathbf{8 8} \%$

\section{GEP-N2}

Naive B cell $(\mathrm{n}=2$, male $)$

Threshold $15 \%$

Deregulation in $\mathbf{1 5 3}$ genes from 22660

Population purity $>99 \%$

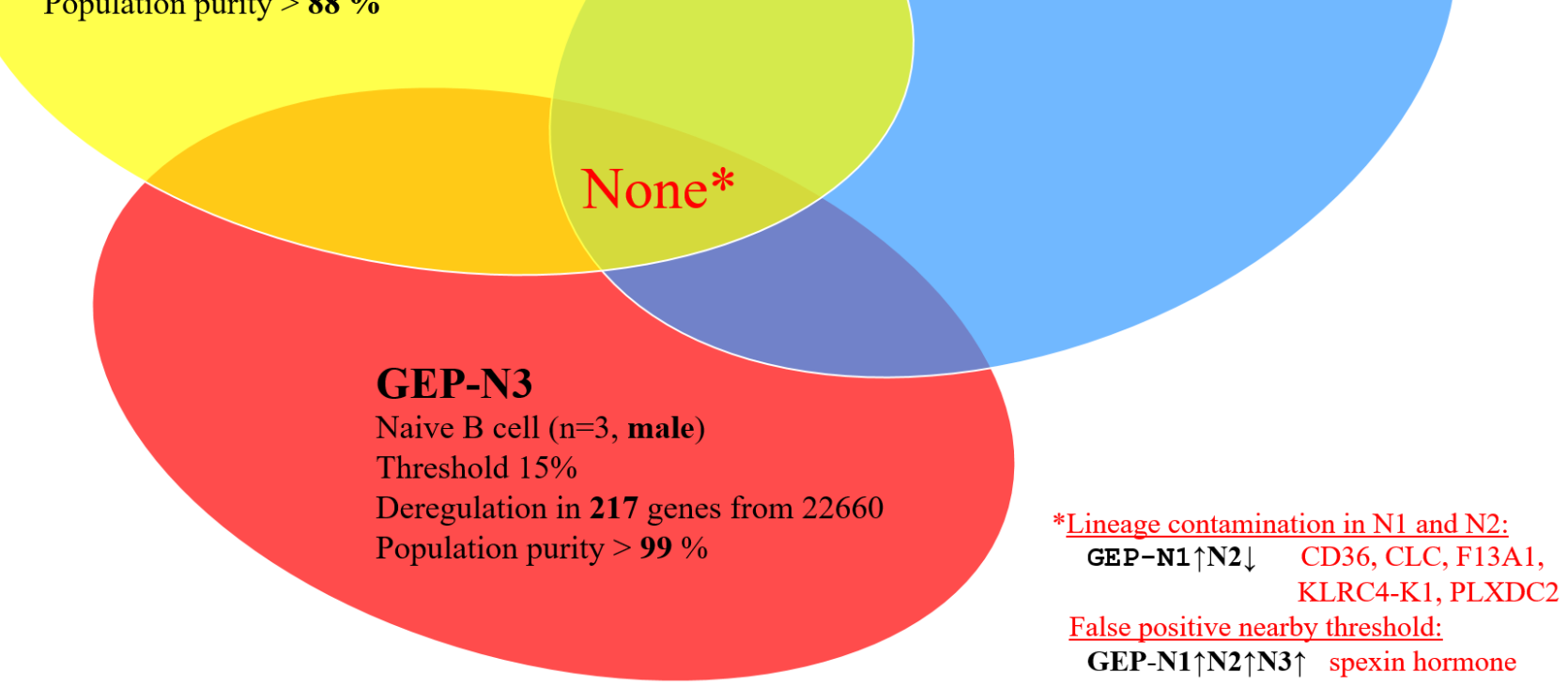

Figure 3: Male specific aging in naive B cells (genome-wide profiles, $\boldsymbol{n}=\mathbf{9}$ ). Venn diagram of results from whole-genome experimental sets GEP-N1, GEP-N2 and GEP-N3 for male specific aging in naive B cells. In the three independent sets, nine male samples were investigated. Arrows indicate expression upregulation and downregulation with age. 
We reviewed the age-specific genes reported by others to be elevated in naive $\mathrm{B}$ cell in much older groups of healthy donors with the age over 78 to 90 years including CCR6, CCR7, CXCR4, CXCR5, CD62L, and Granzyme B genes [6].

We identified all these genes in our experimental sets GEP-N1 and GEP-N2 as lineage-specific contamination. Thus we proved age-specific expression of these genes in our GEP-N3 set with the highest overall cell lineage purity to minimize false positivity. The deregulation of agespecific genes listed above is below $4 \%$ fold change in the samples from GEP-N3 set and therefore, we considered them as unaltered under 60 years of age.

Significantly, we did not observed any deregulation of B cell lineage promoting factors such as IL7R, E2A, EBF or PAX5 that are associated with $\mathrm{B}$ cell decline in humans or animals [12, 13, 21-25]. In general, the agespecific gene deregulation might be longevity-associated and expressed in much older groups of healthy donors with age over 80 years and in centenaries.

As the most of methods, also genome-wide analyses have detection limits, which in turn could limit identification of age-specific genes. Only minor gene alteration might be hidden below the detection threshold and unrecognized in this study. Nevertheless, our genomewide analysis homogeneity indicated result robustness and confident reliability.

We summarize surprising observations that human B lymphocytes remain almost identical on molecular level during 30 to 60 years of age. As the immune system declines, the predispositions to B cell lineage malignancy manifested in some individuals below 60 years of age could not be addressed to natural healthy aging of B lymphocytes. Rather, other aspects might be involved including compromised body environment, declined cell stimulation, immune cell population disorders, clonal accumulations, infection history, life style and other individual behaviour contributing to early onset of aging [26-28].

The molecular identity of young and early aged B cells demonstrated potential of hematopoietic stem cells to generate uncompromised progenitor lymphocytes, naive and mature B cells in early elderly. These are very encouraging findings for general health, because the immunity maintenance does not seems to needed artificial intervention to keep B cells uncompromised in the early elderly.

As reported previously [26-28], more suitable immune stimulations in healthy body environment was proven advantageous. Further research into aging of older elderly is warranted.

\section{MATERIALS AND METHODS}

\section{Cell sorting}

Peripheral blood samples were used to isolate the PBMCs by the density gradient centrifugation on FicollPaque according to manufacturer's recommendation (StemCell Tech). Naive B cells were isolated by MACS

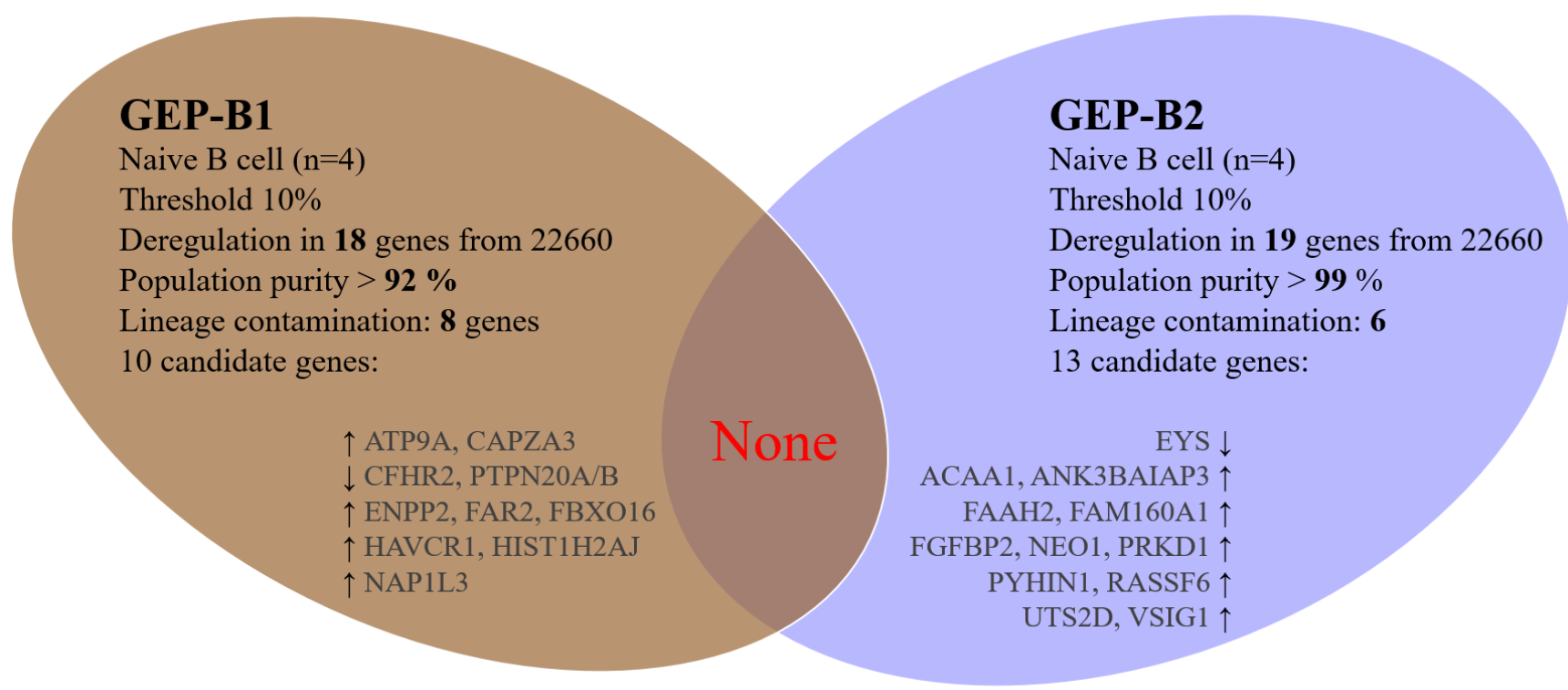

Figure 4: Aging in B cell population (genome-wide profiles, $\boldsymbol{n}=\mathbf{8}$ ). Venn diagram of results from whole-genome experiments GEP-B2 and GEP-B3 for age-specific genes in B cells. Each independent experiment comprised of four samples, together eight samples were investigated. Arrows indicate expression upregulation and downregulation with age. Arrows indicate expression upregulation and downregulation with age. 


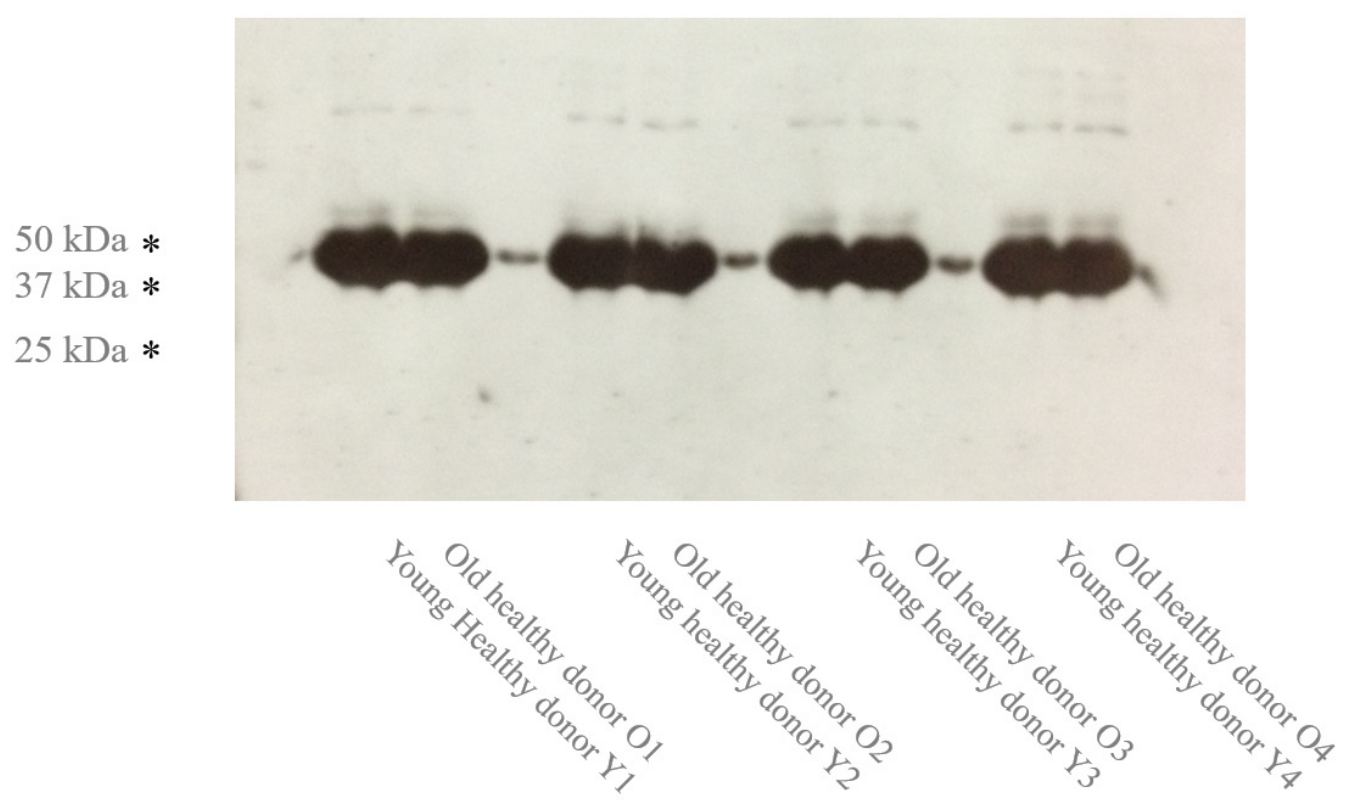

Figure 5: The Age-specific IL7R expression $(\boldsymbol{n}=\mathbf{8})$. Western blotting of four pairs of young and early aged sorted naive B cell samples is shown.
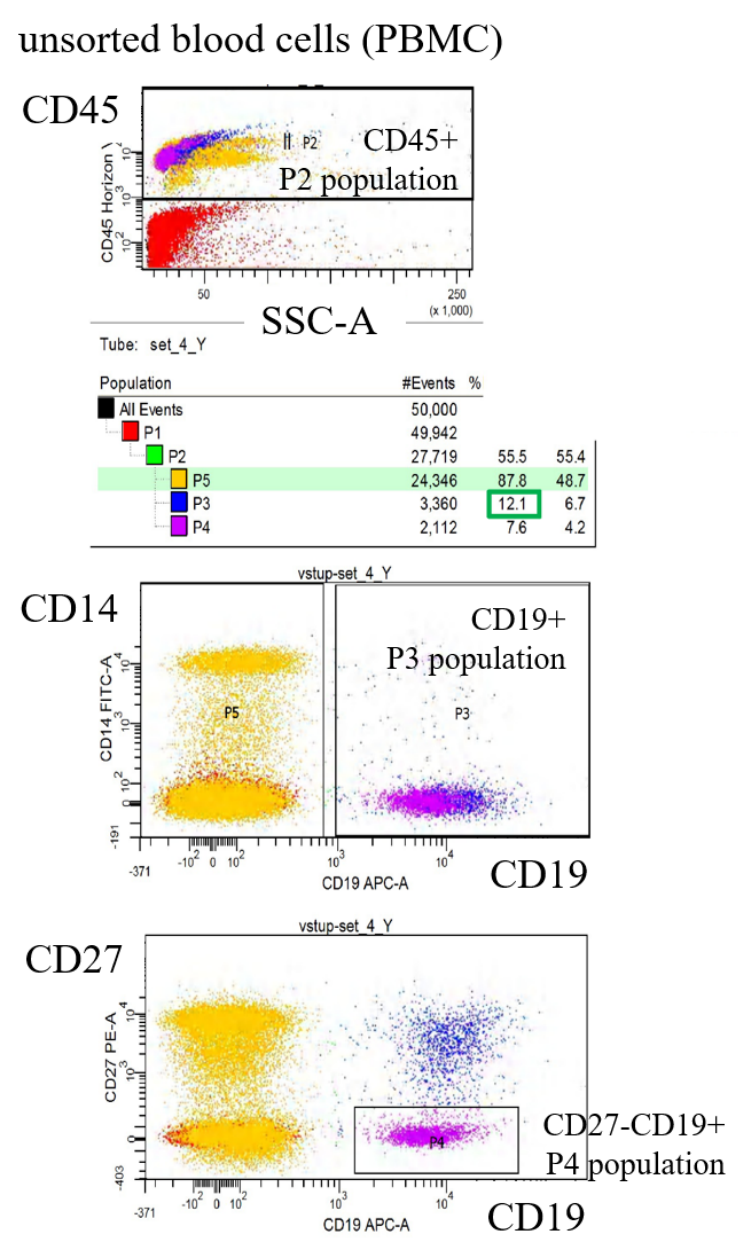

sorted naive B cells (MACS)

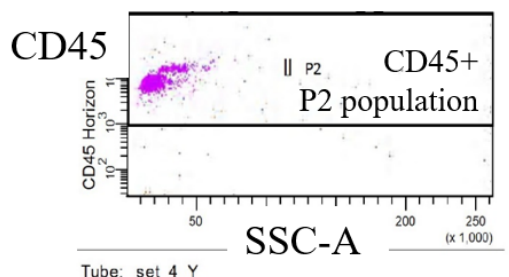

Tube: set_4_Y
Population
\#Events $\%$
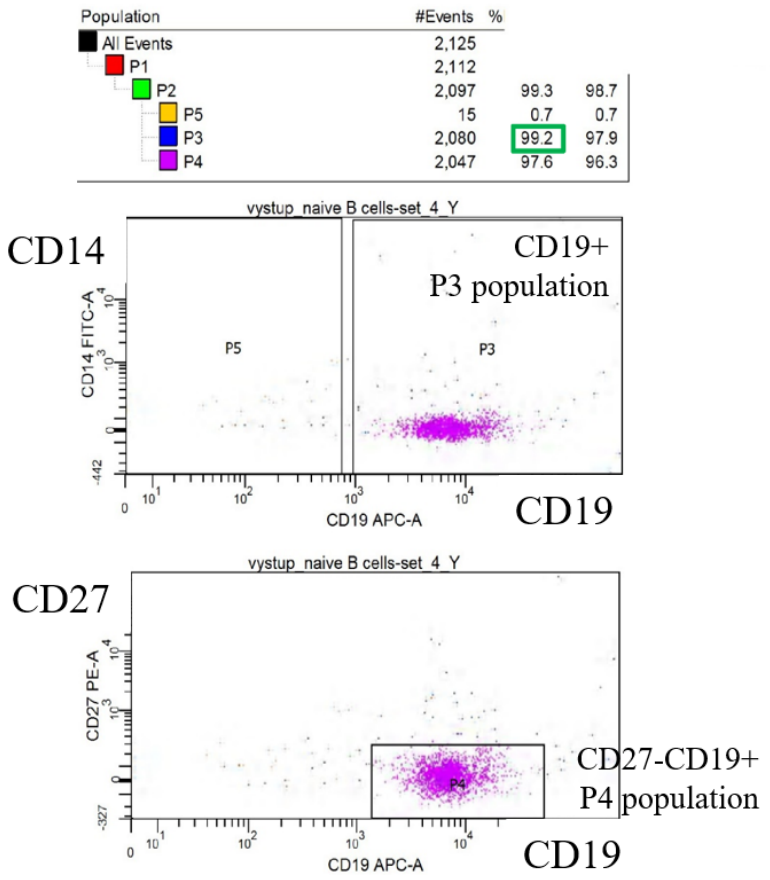

Figure 6: Monitoring of cell population homogeneity by flow cytometry. The lineage contamination was monitored by flow cytometry using CD14, CD3, CD45, CD19 and CD27 antibody. The naive B cells homogeneity was defined by ratio of CD19+CD27 gated population $\mathrm{P} 4$ divided by $\mathrm{CD} 45^{+}$gated population $\mathrm{P} 2\left(\mathrm{~B}\right.$ cells homogeneity $\left.=\mathrm{CD} 19^{+} \mathrm{CD} 27^{-} / \mathrm{CD} 45^{+}=\mathrm{P} 4 / \mathrm{P} 4\right)$. 
negative selection with depletion of the CD2, CD14, CD16, CD27, CD36, CD43, CD235a positive cells according to manufacturer's protocol (Miltenyi). B-cell populations were sorted to the highest purity by using MACS positive selection of CD19 cells. Purity of sorted cells was monitored by ration of $\mathrm{CD} 19^{+} \mathrm{CD} 27^{-}$to $\mathrm{CD} 45^{+}$ by flow cytometry.

\section{Western blotting}

The isolated B cells were immediately lysed with loading buffer, incubated $1 \mathrm{~min}$ at $95^{\circ} \mathrm{C}$, centrifuged $2 \mathrm{~min}$ at $14.000 \mathrm{~g}$, the extract was loaded on $10 \%$ SDS-PAGE, blotted onto nitrocellulose membrane, incubated with 5\% low fat milk, and the primary IL7R antibody (St John's Laboratory) and anti-rabbit secondary antibody peroxidase conjugate (Sigma A6667).

\section{Gene expression analysis (GEP)}

Total RNA was isolated from 500000 cells by QIAGEN RNeasy Mini Kit according to a manufacturer's protocol. RNA concentration was measured by NanoDrop Spectrophotometer, and RNA integrity number (RIN) was calculated using the Agilent 2100 Bioanalyzer (RNA 6000 Nano Kit). Total RNA with absorbance ratio A260/A280 higher than 1.7 and with RIN higher than 7.5 is acceptable for further processing by Ambion WT Expression Kit. Total RNA was used as a template for synthesis of cDNA by reverse transcription. RNA template is degraded using RNase $\mathrm{H}$ leaving intact cDNA. Total of $5.5 \mu \mathrm{g}$ of cDNA is fragmented and labelled using The Affymetrix GeneChip $^{\circledR}$ WT Terminal Labeling Kit. The Human Gene 1.0 ST Array is then washed and stained by Affymetrix fluidics station and scanned by Affymetrix Scanner. Agilent GeneSpring GX 11.5 software for expression data analysis was used. The intensity values (CEL files) were summarised using gene level ExonRMA16 algorithm with quantile normalization and baseline transformation to median of all samples. $T$-test with Benjamini-Hochberg multiple testing correction was used.

Any other details or raw data files are available on the request.

\section{ACKNOWLEDGMENTS}

We thank N. Polokova and R. Pacasova and clinical nurses from the Transfusion and Tissue Bank Faculty Hospital Brno for healthy donor accrual.

\section{CONFLICTS OF INTEREST}

The authors declare no conflicts of interest.

\section{GRANT SUPPORT}

This work was supported by Ministry of Health of the Czech Republic NT14310 (M.P.) and 15-32935A (A.K.), and from the Masaryk University Faculty of Medicine MUNI/11/InGA09/2013 (A.K.). The project was financed from the SoMoPro II programme. The research leading to this invention has acquired a financial grant from the People Programme (Marie Curie Action) of the Seventh Framework Programme of EU (FP 2007-2013) according to the REA Grant Agreement No. 291782. The research is further co-financed by the South-Moravian Region. The study reflects only the author's views and the Union is not liable for any use that may be made of the information contained therein.

\section{Authorship contributions}

M.P. designed the study, conducted the experiments, analysed and interpreted data, wrote the manuscript; A.K. and M.K. reviewed data and wrote the manuscript; P.N., S.B., L.V., M.K., R.V., M.H., P.V., L.R., conducted the experiments and reviewed the manuscript.

\section{REFERENCES}

1. Cancro MP, Hao Y, Scholz JL, Riley RL, Frasca D, DunnWalters DK, Blomberg BB. B cells and aging: molecules and mechanisms. Trends Immunol. 2009; 30: 313-8. doi: 10.1016/j.it.2009.04.005.

2. Czesnikiewicz-Guzik M, Lee W-W, Cui D, Hiruma Y, Lamar DL, Yang Z-Z, Ouslander JG, Weyand CM, Goronzy JJ. T cell subset-specific susceptibility to aging. Clin Immunol. 2008; 127: 107-18. doi: 10.1016/j. clim.2007.12.002.

3. Boyd SD, Liu Y, Wang C, Martin V, Dunn-Walters DK. Human lymphocyte repertoires in ageing. Curr Opin Immunol. 2013; 25: 511-5. doi: 10.1016/j.coi.2013.07.007.

4. Appay V, Sauce D. Naive T cells: the crux of cellular immune aging? Exp Gerontol. 2014; 54: 90-3. doi: 10.1016/j.exger.2014.01.003.

5. Frasca D, Landin AM, Lechner SC, Ryan JG, Schwartz R, Riley RL, Blomberg BB. Aging down-regulates the transcription factor E2A, activation-induced cytidine deaminase, and Ig class switch in human B cells. J Immunol. 2008; 180: 5283-90.

6. Bulati M, Buffa S, Martorana A, Candore G, Lio D, Caruso C, Colonna-Romano G. Trafficking phenotype and production of granzyme $\mathrm{B}$ by double negative $\mathrm{B}$ cells $(\operatorname{IgG}(+) \operatorname{IgD}(-) C D 27(-))$ in the elderly. Exp Gerontol. 2014; 54: 123-9. doi: 10.1016/j.exger.2013.12.011.

7. Martin V, Bryan Wu Y-C, Kipling D, Dunn-Walters D. Ageing of the B-cell repertoire. Philos Trans R Soc Lond, B, Biol Sci. 2015; 370. doi: 10.1098/rstb.2014.0237. 
8. Passtoors WM, van den Akker EB, Deelen J, Maier AB, van der Breggen $R$, Jansen $R$, Trompet $S$, van Heemst D, Derhovanessian E, Pawelec G, van Ommen G-JB, Slagboom PE, Beekman M. IL7R gene expression network associates with human healthy ageing. Immun Ageing. 2015; 12: 21. doi: 10.1186/s12979-015-0048-6.

9. Goldeck D, Oettinger L, Janssen N, Demuth I, SteinhagenThiessen E, Pawelec G. Cytomegalovirus Infection Minimally Affects the Frequencies of B-Cell Phenotypes in Peripheral Blood of Younger and Older Adults. Gerontology. 2016; . doi: 10.1159/000382076.

10. Pawelec G, Goldeck D, Derhovanessian E. Inflammation, ageing and chronic disease. Curr Opin Immunol. 2014; 29: 23-8. doi: 10.1016/j.coi.2014.03.007.

11. Frasca D, Blomberg BB. Aging, cytomegalovirus (CMV) and influenza vaccine responses. Hum Vaccin Immunother. 2015; 12: 682-90. doi: 10.1080/21645515.2015.1105413.

12. Lescale C, Dias S, Maës J, Cumano A, Szabo P, Charron D, Weksler ME, Dosquet C, Vieira P, Goodhardt M. Reduced EBF expression underlies loss of B-cell potential of hematopoietic progenitors with age. Aging Cell. 2010; 9: 410-9. doi: 10.1111/j.1474-9726.2010.00566.x.

13. Miller JP, Allman D. The decline in B lymphopoiesis in aged mice reflects loss of very early B-lineage precursors. J Immunol. 2003; 171: 2326-30.

14. Frasca D, Blomberg BB. Inflammaging decreases adaptive and innate immune responses in mice and humans. Biogerontology. 2016; 17: 7-19. doi: 10.1007/s10522-0159578-8.

15. Colonna-Romano G, Buffa S, Bulati M, Candore G, Lio $\mathrm{D}$, Pellicanò M, Vasto S, Caruso C. B cells compartment in centenarian offspring and old people. Curr Pharm Des. 2010; 16: 604-8.

16. Frasca D, Diaz A, Romero M, Landin AM, Blomberg BB. Age effects on B cells and humoral immunity in humans. Ageing Res Rev. 2011; 10: 330-5. doi: 10.1016/j. arr.2010.08.004.

17. Staedtler F, Hartmann N, Letzkus M, Bongiovanni S, Scherer A, Marc P, Johnson KJ, Schumacher MM. Robust and tissue-independent gender-specific transcript biomarkers. Biomarkers. 2013; 18: 436-45. doi: 10.3109/1354750X.2013.811538.

18. Fan H, Dong G, Zhao G, Liu F, Yao G, Zhu Y, Hou Y. Gender differences of B cell signature in healthy subjects underlie disparities in incidence and course of SLE related to estrogen. J Immunol Res. 2014; 2014: 814598. doi: $10.1155 / 2014 / 814598$.
19. Gombar S, Jung HJ, Dong F, Calder B, Atzmon G, Barzilai N, Tian X-L, Pothof J, Hoeijmakers JHJ, Campisi J, Vijg J, Suh Y. Comprehensive microRNA profiling in B-cells of human centenarians by massively parallel sequencing. BMC Genomics. 2012; 13: 353. doi: 10.1186/1471-216413-353.

20. Frasca D, Diaz A, Romero M, Ferracci F, Blomberg BB. MicroRNAs miR-155 and miR-16 Decrease AID and E47 in B Cells from Elderly Individuals. J Immunol. 2015; 195 : 2134-40. doi: 10.4049/jimmunol.1500520.

21. Blomberg BB, Frasca D. Age effects on mouse and human B cells. Immunol Res. 2013; 57: 354-60. doi: 10.1007/ s12026-013-8440-9.

22. Henry CJ, Marusyk A, DeGregori J. Aging-associated changes in hematopoiesis and leukemogenesis: what's the connection? Aging (Albany NY). 2011; 3: 643-56. doi: 10.18632/aging.100351.

23. Itkin T, Ludin A, Gradus B, Gur-Cohen S, Kalinkovich A, Schajnovitz A, Ovadya Y, Kollet O, Canaani J, Shezen E, Coffin DJ, Enikolopov GN, Berg T, et al. FGF-2 expands murine hematopoietic stem and progenitor cells via proliferation of stromal cells, c-Kit activation and CXCL12 downregulation. Blood. 2012 [cited 2012 Jun 17]; . doi: 10.1182/blood-2011-11-394692.

24. Linton PJ, Dorshkind K. Age-related changes in lymphocyte development and function. Nat Immunol. 2004; 5: 133-9. doi: 10.1038/ni1033.

25. Wagner W, Bork S, Horn P, Krunic D, Walenda T, Diehlmann A, Benes V, Blake J, Huber F-X, Eckstein V, Boukamp P, Ho AD. Aging and replicative senescence have related effects on human stem and progenitor cells. PLoS ONE. 2009; 4: e5846. doi: 10.1371/journal.pone.0005846.

26. Müller L, Pawelec G. Aging and immunity - impact of behavioral intervention. Brain Behav Immun. 2014; 39: 8-22. doi: 10.1016/j.bbi.2013.11.015.

27. Moss $\mathrm{P}$. The emerging role of cytomegalovirus in driving immune senescence: a novel therapeutic opportunity for improving health in the elderly. Curr Opin Immunol. 2010; 22: 529-34. doi: 10.1016/j.coi.2010.07.001.

28. Prieto-Hinojosa A, Knight A, Compton C, Gleeson M, Travers PJ. Reduced thymic output in elite athletes. Brain Behav Immun. 2014; 39: 75-9. doi: 10.1016/j. bbi.2014.01.004. 